\title{
Moderate weight change following diabetes diagnosis and 10 year incidence of cardiovascular disease and mortality
}

\author{
Jean Strelitz ${ }^{1}$ (1) • Amy L. Ahern ${ }^{1} \cdot$ Gráinne H. Long $^{2} \cdot$ Matthew J. L. Hare ${ }^{3} \cdot$ Greg Irving $^{4} \cdot$ Clare E. Boothby $^{1}$. \\ Nicholas J. Wareham ${ }^{1}$. Simon J. Griffin ${ }^{1,4}$
}

Received: 11 December 2018 / Accepted: 26 March 2019 / Published online: 7 May 2019

(C) The Author(s) 2019

\begin{abstract}
Aims/hypothesis Adults with type 2 diabetes are at high risk of developing cardiovascular disease (CVD). Evidence of the impact of weight loss on incidence of CVD events among adults with diabetes is sparse and conflicting. We assessed weight change in the year following diabetes diagnosis and estimated associations with 10 year incidence of CVD events and all-cause mortality.

Methods In a cohort analysis among 725 adults with screen-detected diabetes enrolled in the Anglo-Danish-Dutch Study of Intensive Treatment in People with Screen-Detected Diabetes in Primary Care (ADDITION)-Cambridge trial, we estimated HRs for weight change in the year following diabetes diagnosis and 10 year incidence of CVD $(n=99)$ and all-cause mortality $(n=95)$ using Cox proportional hazards regression. We used linear regression to estimate associations between weight loss and CVD risk factors. Models were adjusted for age, sex, baseline BMI, smoking, occupational socioeconomic status, cardio-protective medication use and treatment group.

Results Loss of $\geq 5 \%$ body weight in the year following diabetes diagnosis was associated with improvements in $\mathrm{HbA}_{1 \mathrm{c}}$ and blood lipids and a lower hazard of CVD at 10 years compared with maintaining weight (HR 0.52 [95\% CI 0.32, 0.86]). The associations between weight gain vs weight maintenance and CVD (HR 0.41 [95\% CI 0.15, 1.11]) and mortality (HR 1.63 [95\% CI $0.83,3.19])$ were less clear.

Conclusions/interpretation Among adults with screen-detected diabetes, loss of $\geq 5 \%$ body weight during the year after diagnosis was associated with a lower hazard of CVD events compared with maintaining weight. These results support the hypothesis that moderate weight loss may yield substantial long-term CVD reduction, and may be an achievable target outside of specialist-led behavioural treatment programmes.
\end{abstract}

Keywords Cardiovascular disease $\cdot$ Diabetes $\cdot$ Epidemiology $\cdot$ Weight loss

Electronic supplementary material The online version of this article (https://doi.org/10.1007/s00125-019-4886-1) contains peer-reviewed but unedited supplementary material, which is available to authorised users.

Jean Strelitz

jean.strelitz@mrc-epid.cam.ac.uk

1 MRC Epidemiology Unit, Institute of Metabolic Science, Cambridge Biomedical Campus, University of Cambridge School of Clinical Medicine, Box 285, Cambridge CB2 0QQ, UK

2 AstraZeneca Pharmaceuticals, Cambridge, UK

3 Departments of Endocrinology, Diabetes and Vascular Medicine, Monash Health, Melbourne, VIC, Australia

4 Primary Care Unit, Institute of Public Health, University of Cambridge School of Clinical Medicine, Cambridge, UK

\section{Abbreviations}

ADDITION-Cambridge Anglo-Danish-Dutch Study of Intensive Treatment in People with Screen-Detected Diabetes in Primary

Care-Cambridge

CVD

GP

Look AHEAD

MRC

NHS

NIHR
Cardiovascular disease

General practice

Action for Health in Diabetes Medical Research Council National Health Service National Institute for Health Research 


\section{Research in context}

\section{What is already known about this subject?}

- Cardiovascular disease (CVD) is the most common diabetes complication and accounts for nearly half of total treatment costs globally. Being overweight or obese are key risk factors for diabetes and CVD

- Evidence as to whether weight loss among people with type 2 diabetes leads to reduction in CVD events is sparse and conflicting

\section{What is the key question?}

- Is weight loss following diabetes diagnosis associated with incidence of CVD?

\section{What are the new findings?}

- Loss of $\geq 5 \%$ body weight in the year following diabetes diagnosis was associated with improvements in risk factors and a $48 \%$ lower hazard of CVD at 10 years

\section{How might this impact on clinical practice in the foreseeable future?}

- The results support a greater focus towards achieving weight loss in people with newly diagnosed diabetes

ROSE

SES

UKPDS

\section{Introduction}

Adults with type 2 diabetes are at high risk of developing cardiovascular disease (CVD) [1]. CVD is the most common and most costly diabetes complication, accounting for nearly half of total treatment costs globally [2,3]. Weight loss has been shown to improve CVD risk factors such as $\mathrm{HbA}_{1 \mathrm{c}}$, blood lipids and BP among people with type 2 diabetes [4-6] and may also lead to diabetes remission [7]. However, while improvements in these risk factors have been demonstrated in short-term studies $[4,8]$, few studies have assessed CVD events.

The existing literature on change in weight and CVD among adults with diabetes is limited, and studies have shown inconclusive and inconsistent associations of weight loss and CVD risk [9-12]. In the Action for Health in Diabetes (Look AHEAD) randomised trial among obese adults with clinically diagnosed diabetes of 7 years' duration, the behavioural intervention assessed in the trial did not appear to reduce CVD incidence [6], although participants who lost at least $10 \%$ of their body weight in 1 year had a $21 \%$ lower 10 year risk of CVD compared with those with stable weight or weight gain [10]. However, weight loss observed among trial participants may not be representative of what would be achievable in the general population in the absence of an intensive intervention programme. Furthermore, as population-based screening for type 2 diabetes has become increasingly common, understanding the impact of weight changes early in the diabetes disease trajectory is needed to inform clinical practice at the time of diagnosis, when patients may be more receptive to care [13].

Considering the challenge of controlling CVD risk factors among individuals with established diabetes and the risks associated with intensification of therapy $[14,15]$, the year following diagnosis may be a critical time to establish healthy behaviours that lead to long-term comorbidity reduction. Weight loss during this period may result in a legacy effect, whereby improvements in risk factors early in the course of the disease yield long-term CVD benefits. In the UK Prospective Diabetes Study (UKPDS), intensive glucose control following diabetes diagnosis was associated with lower risk of CVD 10 years after the trial, even though differences in glucose control were not maintained after the end of the trial [16]. The Diabetes Care in General Practice trial of people with a new diagnosis of diabetes showed no association between 13 year CVD incidence and weight loss achieved through a 6 year intensive intervention [17]. However, this study had a relatively small sample size $(N=444)$ and participants had to survive until the end of the 6 year intervention period in order to be followed up for CVD, which might have resulted in a healthier study population relative to the target population [18]. The Retrospective Study of Cardiovascular Events Related to the Use of Glucose-Lowering Drug Treatment in Primary Care (ROSE) cohort study of individuals in Swedish primary care $(N=8486)$ showed that weight loss in the 18 months following diabetes diagnosis had no protective association with CVD events during a median follow-up time of 4.6 years; however, weight gain was associated with $63 \%$ higher hazard of CVD [12]. Given the mixed results of studies of weight loss and CVD and the limited generalisability of results from intensive weight loss trials, 
additional population-based research is needed to characterise the impacts of weight loss after diabetes diagnosis on longterm CVD incidence.

Using data from a population-based study of screening for type 2 diabetes, the Anglo-Danish-Dutch Study of Intensive Treatment in People with Screen-Detected Diabetes in Primary Care (ADDITION)-Cambridge [19], we assessed the association of weight change in the year following diabetes diagnosis and 10 year CVD and mortality incidence, and the impact of weight change on CVD risk factors (BP, blood lipid and $\mathrm{HbA}_{1 \mathrm{c}}$ levels) at 1 year and 5 years following diagnosis.

\section{Methods}

ADDITION-Cambridge (ISRCTN86769081) is a pragmatic cluster-randomised trial comparing multifactorial intervention vs routine care among people with screen-detected diabetes from 49 general practices (GPs) in eastern England [19]. The present study is an observational analysis of the trial cohort. A validated risk score was used to identify eligible individuals aged 40-69 years who were at high risk of diabetes, using the electronic records of participating GPs [20]. From 2002 to $2006,33,539$ high-risk individuals were invited to attend a stepwise screening programme; 24,654 (74\%) took part [21]. During screening, 867 participants were diagnosed with type 2 diabetes using the 1999 WHO criteria [22] and all consented to enrol in the study. The GPs were cluster-randomised to intensive treatment $(n=26)$ or routine care $(n=23)$. In the routine care group, GPs were advised to follow current UK guidelines for diabetes management [23-25]. Intensive treatment included more frequent consultations, provision of educational materials and GP-based academic-detailing sessions encouraging earlier use of medication to improve control of risk factors. The intervention did not include behavioural treatment. Written informed consent was obtained from all participants and ethics approval was obtained from the research ethics committees in Cambridge (ref. 01/063), Huntingdonshire (ref. 00/609), Peterborough and Fenland (ref. P01/95), West Essex (ref. 1511-0103), North and Mid Essex (ref. MH395 MREC02/5/54), West Suffolk (ref. 03/ 002), and Hertfordshire and Bedfordshire (ref. EC03623) Local Research Ethics Committees and the Eastern MultiCentre Research Ethics Committee (ref. 02/5/54).

\section{Measurements}

Anthropometric, biochemical, clinical and questionnairebased measures were taken at the time of diabetes diagnosis (baseline) and after 1 and 5 years [19]. Sociodemographic information (age, sex, occupation and ethnicity), smoking status and prescribed pharmacological treatment were selfreported via standardised questionnaires. Information on pharmacological treatment at 5 years was supplemented using GP electronic records. Socioeconomic status (SES) was defined according to the Registrar General's occupation-based classification: 'professional, managerial and technical', 'skilled-manual and non-manual' and 'partly skilled or unskilled' [26]. Clinical and anthropometric measures were performed by trained staff, according to standard procedures [19].

\section{CVD and mortality outcomes}

The outcomes of interest were CVD events and all-cause mortality. The composite CVD outcome included cardiovascular mortality, non-fatal myocardial infarction, non-fatal stroke, non-traumatic amputation, and revascularisation (both invasive cardiovascular and peripheral vascular procedures). Incidence of CVD events and mortality was ascertained from the date of diabetes diagnosis until 31 December 2014. Participants were flagged using National Health Service (NHS) patient numbers for mortality surveillance by the Office for National Statistics. Possible CVD outcomes were identified via searches of GP notes, hospital discharge summaries, hospital notes, electrocardiograms, laboratory results, death certificates, autopsies and the Myocardial Ischaemia National Audit Project (MINAP) [27]. All events were independently adjudicated using standardised case report forms.

\section{Statistical analysis}

Of the 867 adults enrolled in the ADDITION-Cambridge study, we were unable to include 137 for whom we could not determine weight change, as they were missing data on weight measurements at baseline or 1 year. We also excluded individuals who had a CVD event in the first year in the study $(n=5)$, as this was when weight change was measured. Therefore, this study included 725 participants with 99 CVD events. Mortality analyses also excluded deaths occurring within 1 year after weight change was assessed $(n=2)$, as weight loss might have been due to underlying disease; this left a total of 95 all-cause mortalities during the study period.

We assessed predictors of missing weight information by comparing distributions of factors measured at baseline between individuals who were and who were not missing weight measurements.

The proportion of weight change was determined by subtracting weight at baseline from weight at 1 year, then dividing by weight at baseline. We defined weight change categorically as $>2 \%$ gain, maintained weight ( $\leq 2 \%$ gain or $<2 \%$ loss), $\geq 2 \%$ to $<5 \%$ loss, $\geq 5 \%$ to $<10 \%$ loss, and $\geq 10 \%$ loss. These categories were chosen to examine the recommended weight loss target of 5-10\% [28, 29] and compare it against greater or lesser weight loss, while separating those who gained weight from those who maintained their baseline weight. 
Weight change, CVD events and all-cause mortality We used Cox proportional hazards regression to estimate HRs for category of weight change, 10 year incidence of CVD events and 10 year all-cause mortality. Due to the small numbers of CVD events among participants who lost the most weight, we combined the $\geq 5 \%$ to $<10 \%$ loss and $\geq 10 \%$ loss categories.

The timescale was the number of days since diabetes diagnosis. Person-time at risk began 1 year after diabetes diagnosis and ended at the time of the event, death or 31 December 2014. We assessed the proportional hazards assumption by modelling an interaction term between the natural log of time and each covariate, which indicated no departures from proportional hazards. All models adjusted for confounders identified using a directed acyclic graph [30]: age at baseline (continuous), sex (female, male), trial group (intensive treatment, routine care), baseline occupational SES ('professional, managerial and technical', 'skilled-manual and non-manual' and 'partly skilled or unskilled'), BMI at baseline (continuous, coded as a quadratic term), cigarette-smoking status at 1 year (current, former, never), and use of antihypertensive (yes, no), glucose-lowering (yes, no) and lipid-lowering (yes, no) medication at 1 year. Clustering of individuals within GPs was accounted for using a robust cluster variance estimator.

To assess heterogeneity of associations by age, we modelled an interaction term between weight change and age at diagnosis. As past research has shown negative impacts of weight loss on mortality among older adults [31-33], we performed separate analyses to estimate the associations of interest among those aged $\geq 65$ years at the time of diabetes diagnosis. We were unable to stratify by age at diagnosis $<65$ years owing to the small number of cases in this age group.

In a sensitivity analysis, we used multiple imputation by chained equations [34] to estimate associations among the full cohort including the 137 individuals with missing weight information. The imputation models included covariates for weight change category; sex; occupational SES; baseline BMI; smoking; treatment group; antihypertensive, glucoselowering and lipid-lowering medication use at 1 year; outcome status; and the Nelson-Aalen estimate of cumulative hazard. We generated 20 imputed datasets and used these to estimate HRs in the full cohort. Separate imputation models were fit where the outcome was all-cause mortality. We also assessed the robustness of our results to changes in weight after the first year in the study by adjusting for weight change from year 1 to year 5 . Additional sensitivity analyses excluded individuals with a history of myocardial infarction or stroke prior to diagnosis of diabetes $(n=77)$; separate analyses excluded revascularisation and amputations from the composite CVD outcome $(n=37)$ in order to estimate HRs for a composite of stroke, myocardial infarction or cardiovascular death. To evaluate the association of weight change and CVD occurring in the presence of the competing risk of non-CVD mortality, we estimated subdistribution HRs [35].
Weight loss and CVD risk factors We used linear regression models to estimate the associations between percentage weight loss in the year following diabetes diagnosis and CVD risk factors $\left(\mathrm{HbA}_{1 \mathrm{c}}\right.$, systolic and diastolic $\mathrm{BP}$, triacylglycerols, total cholesterol and LDL-cholesterol) at 1 year and 5 years. Percentage weight change categories were defined as above.

The adjustment set was the same as in the proportional hazards models, except that each model was adjusted for relevant medication use in the year the outcome was measured (e.g. glucose-lowering agents for $\mathrm{HbA}_{1 \mathrm{c}}$, antihypertensive medication for BP, and lipid-lowering medication for lipid levels), rather than adjusting for each type of medication use. Separate analyses were stratified by medication use at 1 year and 5 years to assess possible heterogeneity of the associations. Sensitivity analyses were conducted: (1) using multiple imputation by chained equations [34] to estimate the associations of percentage weight change and the CVD risk factors among the full cohort; [2] by adjusting for baseline values of the risk factors.

\section{Results}

Of the 99 first incident CVD events, 36 were revascularisations, 24 were strokes, 21 were CVD deaths, 17 were myocardial infarctions and one was an amputation. Of the 95 incident deaths during the study period, 31 were related to CVD, 45 to cancer and 19 to another cause. Mean follow-up time was 9.8 years.

Of the 725 study participants with non-missing weight information and no CVD event during the first year in the study, $62 \%$ were male, $97 \%$ were white and the mean age at diagnosis of diabetes was 61 years. At baseline 34.8\% had a professional occupation, $23.0 \%$ had a skilled occupation and $42.3 \%$ had an unskilled occupation. Mean weight change (SD) during the study period was $-3.6 \mathrm{~kg}(5.5 \mathrm{~kg})$ at 1 year (Table 1) and $-4.1 \mathrm{~kg}(7.1 \mathrm{~kg})$ at 5 years (not shown). Use of lipidlowering and glucose-lowering medication increased throughout the study period (Table 1). As distributions of weight changes and CVD risk factors were similar between men and women (electronic supplementary material [ESM] Table 1), all participants were analysed together. CVD risk factors largely improved across the study period. Those who lost $\geq 5 \%$ body weight had somewhat larger decreases in systolic BP at 1 year and 5 years compared with the other groups (Table 2). After stratifying by category of weight change in the first year in the study, the mean weight at 5 years in the study was similar to the mean weight at 1 year in the study (ESM Table 2).

Missing weight information at baseline or 1 year was associated with SES and smoking: unskilled workers were more likely to have missing weight compared with professional 
Table 1 Characteristics of individuals with type 2 diabetes at the time of diagnosis (baseline) and 1 year later by weight change category in the year following diabetes diagnosis

\begin{tabular}{|c|c|c|c|c|c|c|c|c|c|c|}
\hline \multirow[t]{2}{*}{ Characteristic } & \multicolumn{2}{|c|}{ Full cohort $(N=725)$} & \multicolumn{2}{|c|}{$\begin{array}{l}\text { Gained }>2 \% \text { weight } \\
(n=79)\end{array}$} & \multicolumn{2}{|c|}{$\begin{array}{l}\text { Maintained weight }{ }^{\mathrm{a}} \\
(n=222)\end{array}$} & \multicolumn{2}{|c|}{$\begin{array}{l}\text { Lost } \geq 2 \% \text { to }<5 \% \\
\text { weight }(n=183)\end{array}$} & \multicolumn{2}{|c|}{$\begin{array}{l}\text { Lost } \geq 5 \% \text { weight } \\
(n=241)\end{array}$} \\
\hline & Baseline & 1 year & Baseline & 1 year & Baseline & 1 year & Baseline & 1 year & Baseline & 1 year \\
\hline \multicolumn{11}{|l|}{ Sex, $n(\%)$} \\
\hline Female & $279(38.5)$ & - & $30(38.0)$ & - & $71(32.0)$ & - & $64(35.0)$ & - & $114(47.3)$ & - \\
\hline Male & $446(61.5)$ & - & $49(62.0)$ & - & $151(68.0)$ & - & $119(65.0)$ & - & $127(52.7)$ & - \\
\hline Missing & $0(0.0)$ & - & $0(0.0)$ & - & $0(0.0)$ & - & $0(0.0)$ & - & $0(0.0)$ & - \\
\hline Age, years & $61.1(7.1)$ & - & $60.8(7.1)$ & - & $60.4(7.5)$ & - & $61.0(7.3)$ & - & $61.8(6.4)$ & - \\
\hline Missing, $n(\%)$ & $0(0.0)$ & - & $0(0.0)$ & - & $0(0.0)$ & - & $0(0.0)$ & - & $0(0.0)$ & - \\
\hline BMI, $\mathrm{kg} / \mathrm{m}^{2}$ & $33.4(5.6)$ & $32.2(5.5)$ & $32.3(6.3)$ & $33.8(6.6)$ & $32.8(5.4)$ & $32.8(5.4)$ & $33.4(5.4)$ & $32.4(5.2)$ & $34.2(5.6)$ & $30.9(5.1)$ \\
\hline Missing, $n(\%)$ & $1(0.1)$ & $0(0.0)$ & $0(0.0)$ & $0(0.0)$ & $0(0.0)$ & $1(0.5)$ & $1(0.5)$ & $0(0.0)$ & $0(0.0)$ & $0(0.0)$ \\
\hline Weight, kg & $94.6(17.6)$ & $91.0(17.4)$ & $91.5(18.6)$ & $95.8(18.9)$ & $94.3(17.5)$ & $94.0(17.5)$ & $95.0(16.1)$ & $91.9(15.6)$ & $95.7(18.3)$ & $86.1(16.8)$ \\
\hline Missing, $n(\%)$ & $0(0.0)$ & $0(0.0)$ & $0(0.0)$ & $0(0.0)$ & $0(0.0)$ & $0(0.0)$ & $0(0.0)$ & $0(0.0)$ & $0(0.0)$ & $0(0.0)$ \\
\hline $\begin{array}{l}\text { Weight change from } \\
\text { baseline, } \mathrm{kg}\end{array}$ & - & $-3.6(5.5)$ & - & $4.3(2.0)$ & - & $-0.27(1.0)$ & - & $-3.1(0.9)$ & - & $-9.6(4.7)$ \\
\hline \multicolumn{11}{|l|}{ Smoking, $n(\%)$} \\
\hline Current & $120(16.6)$ & $106(14.8)$ & $12(15.2)$ & $9(11.5)$ & $34(15.3)$ & $27(12.4)$ & $31(16.9)$ & $32(17.6)$ & $43(17.8)$ & $38(16.0)$ \\
\hline Former & $337(46.5)$ & $343(48.0)$ & $27(34.2)$ & $29(37.2)$ & $124(55.9)$ & $127(58.3)$ & $86(47.0)$ & $85(46.7)$ & $100(41.5)$ & $102(43.0)$ \\
\hline Never & $268(37.0)$ & $266(37.2)$ & $40(50.6)$ & $40(51.3)$ & $64(28.8)$ & $64(29.4)$ & $66(36.1)$ & $65(35.7)$ & $98(40.7)$ & $97(40.9)$ \\
\hline Missing & $0(0.0)$ & $10(1.4)$ & $0(0.0)$ & $1(1.3)$ & $0(0.0)$ & $4(1.8)$ & $0(0.0)$ & $1(0.5)$ & $0(0.0)$ & $4(1.7)$ \\
\hline \multicolumn{11}{|l|}{ Alcohol } \\
\hline Units/week & $7.5(10.8)$ & $6.6(9.8)$ & $10.0(13.6)$ & $9.6(13.5)$ & $9.0(11.8)$ & $8.4(11.1)$ & $7.1(10.6)$ & $5.9(8.6)$ & $5.6(8.3)$ & $4.6(7.3)$ \\
\hline Missing, $n(\%)$ & $11(1.5)$ & $17(2.3)$ & $1(1.3)$ & $2(2.5)$ & $4(1.8)$ & $5(2.3)$ & $3(1.6)$ & $5(2.7)$ & $3(1.2)$ & $5(2.1)$ \\
\hline \multicolumn{11}{|c|}{ Prescribed medication use, $n(\%)$} \\
\hline \multicolumn{11}{|c|}{ Glucose-lowering } \\
\hline Yes & $2(0.3)$ & $216(30.6)$ & $1(1.3)$ & $31(40.8)$ & $0(0.0)$ & $63(29.4)$ & $1(0.5)$ & $60(33.7)$ & $0(0.0)$ & $62(26.2)$ \\
\hline No & $723(99.7)$ & 489 (69.4) & $78(98.7)$ & $45(59.2)$ & $222(100.0)$ & $151(70.6)$ & $182(99.5)$ & $118(66.3)$ & $241(100.0)$ & $175(73.8)$ \\
\hline Missing & $0(0.0)$ & $20(2.8)$ & $0(0.0)$ & $3(3.8)$ & $0(0.0)$ & $8(3.6)$ & $0(0.0)$ & $5(2.7)$ & $0(0.0)$ & $4(1.7)$ \\
\hline \multicolumn{11}{|l|}{ Antihypertensive } \\
\hline Yes & $414(57.1)$ & $485(68.8)$ & $51(64.6)$ & $56(73.7)$ & $121(54.5)$ & $136(63.6)$ & $111(60.7)$ & $130(73.0)$ & $131(54.4)$ & $163(68.8)$ \\
\hline No & $311(42.9)$ & $220(31.2)$ & $28(35.4)$ & $20(26.3)$ & $101(45.5)$ & $78(36.4)$ & $72(39.3)$ & $48(27.0)$ & $110(45.6)$ & $74(31.2)$ \\
\hline Missing & $0(0.0)$ & $20(2.8)$ & $0(0.0)$ & $3(3.8)$ & $0(0.0)$ & $8(3.6)$ & $0(0.0)$ & $5(2.7)$ & $0(0.0)$ & $4(1.7)$ \\
\hline \multicolumn{11}{|l|}{ Lipid-lowering } \\
\hline Yes & 173 (23.9) & $462(65.5)$ & $18(22.8)$ & $51(67.1)$ & $58(26.1)$ & $123(57.5)$ & $48(26.2)$ & $128(71.9)$ & $49(20.3)$ & $160(67.5)$ \\
\hline No & $552(76.1)$ & $243(34.5)$ & $61(77.2)$ & $25(32.9)$ & 164 (73.9) & $91(42.5)$ & $135(73.8)$ & $50(28.1)$ & 192 (79.7) & $77(32.5)$ \\
\hline Missing & $0(0.0)$ & $20(2.8)$ & $0(0.0)$ & $3(3.8)$ & $0(0.0)$ & $8(3.6)$ & $0(0.0)$ & $5(2.7)$ & $0(0.0)$ & $4(1.7)$ \\
\hline
\end{tabular}

Data are from a prospective cohort analysis of participants recruited in ADDITION-Cambridge between 2002 and 2014

Data are presented as mean (SD) except where otherwise stated

${ }^{a}$ Defined as $\leq 2 \%$ gain or $<2 \%$ loss

workers, and non-smokers were less likely to have missing weight compared with current smokers (ESM Table 3).

\section{Weight change, 10 year CVD events and all-cause mortality}

Losing $\geq 5 \%$ of body weight was associated with a lower hazard of 10 year CVD events compared with maintaining weight (HR 0.52 [95\% CI 0.32, 0.86]). Associations between weight gain and 10 year CVD incidence (HR 0.41 [95\% CI 0.15, 1.11]) and all-cause mortality (HR 1.63 [95\% CI 0.83, 3.19]) were less apparent. There were no associations between weight loss and all-cause mortality (Table 3 ). The associations were similar after adjusting for changes in weight between 1 and 5 years in the study (ESM Table 4). Results from analyses with multiple imputation of missing information also showed similar associations (ESM Table 5). Analyses excluding participants with self-reported history of CVD were also similar 


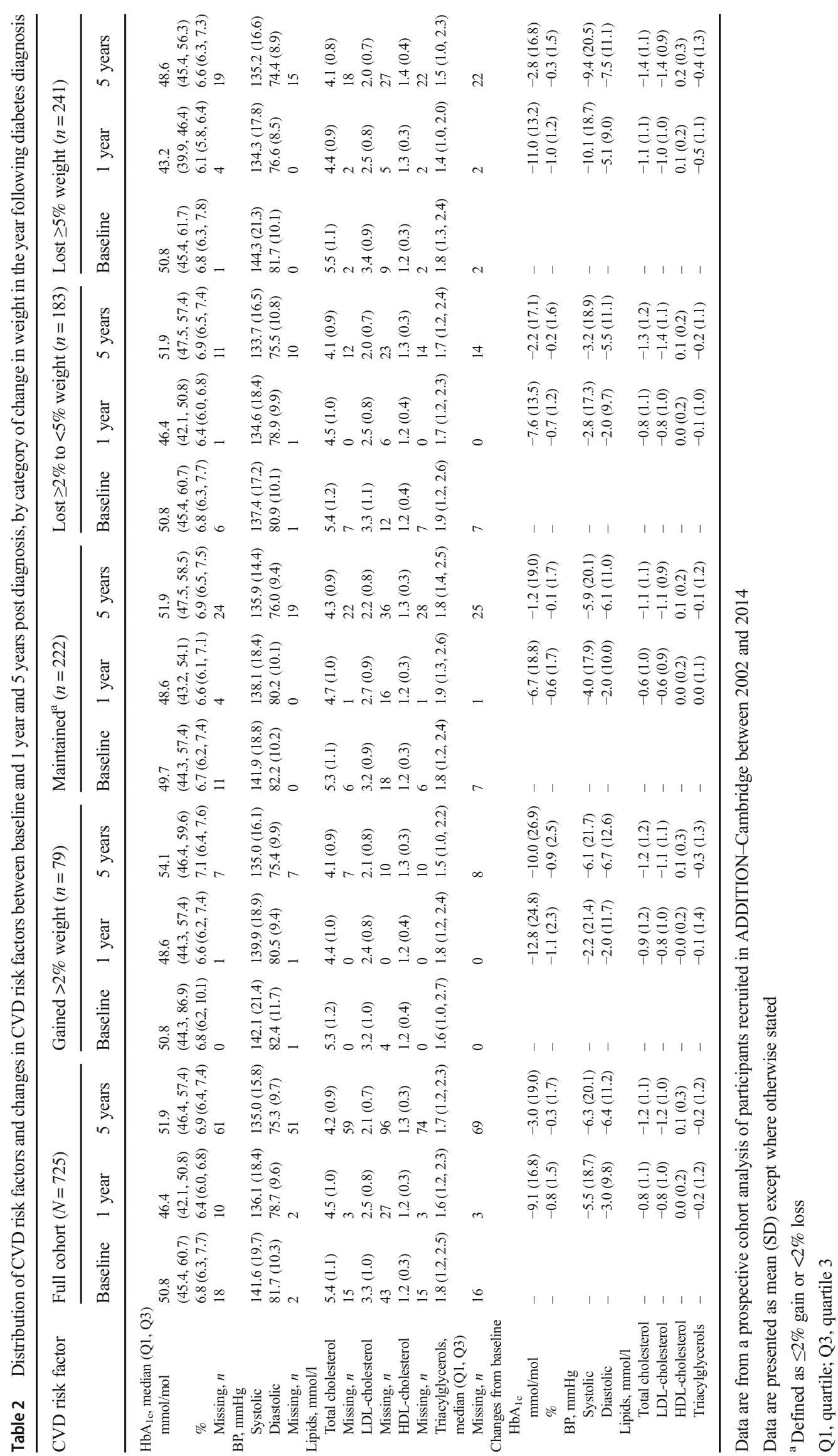


Table 3 HRs for the associations of change in weight in the year following diabetes diagnosis and 10 year incidence of CVD and mortality

\begin{tabular}{|c|c|c|c|c|}
\hline \multirow[t]{2}{*}{ Sample } & \multicolumn{2}{|c|}{10 year CVD incidence } & \multicolumn{2}{|c|}{10 year all-cause mortality } \\
\hline & Cases/total, $n$ & $\operatorname{HR}(95 \% \mathrm{CI})^{\mathrm{a}}$ & Cases/total, $n$ & $\operatorname{HR}(95 \% \mathrm{CI})^{\mathrm{a}}$ \\
\hline \multicolumn{5}{|l|}{ Full cohort $(N=725)$} \\
\hline \multicolumn{5}{|l|}{ Weight change } \\
\hline Gained $>2 \%$ & $6 / 75$ & $0.41(0.15,1.11)$ & $13 / 75$ & $1.63(0.83,3.19)$ \\
\hline Maintained $^{\mathrm{b}}$ & $40 / 210$ & 1.00 & $23 / 210$ & 1.00 \\
\hline Lost $\geq 2 \%$ to $<5 \%$ & $26 / 173$ & $0.79(0.43,1.46)$ & $22 / 172$ & $1.08(0.60,1.93)$ \\
\hline Lost $\geq 5 \%$ & $22 / 229$ & $0.52(0.32,0.86)$ & $30 / 228$ & $1.12(0.52,2.37)$ \\
\hline \multicolumn{5}{|l|}{ Age $\geq 65$ years $(n=278)$} \\
\hline \multicolumn{5}{|l|}{ Weight change } \\
\hline Gained $>2 \%$ & $4 / 26$ & $0.66(0.20,2.15)$ & $9 / 26$ & $2.07(0.81,5.30)$ \\
\hline Maintained $^{\mathrm{b}}$ & $20 / 78$ & 1.00 & $14 / 78$ & 1.00 \\
\hline Lost $\geq 2 \%$ to $<5 \%$ & $16 / 72$ & $0.87(0.41,1.87)$ & $18 / 72$ & $1.32(0.63,2.78)$ \\
\hline Lost $\geq 5 \%$ & $8 / 84$ & $0.39(0.16,0.94)$ & $15 / 84$ & $1.03(0.37,2.81)$ \\
\hline
\end{tabular}

Data are from a prospective cohort analysis of participants recruited in ADDITION-Cambridge between 2002 and 2014

Sample sizes comprise only cases where data are available for weight change, age, sex, baseline SES, baseline BMI, smoking at 1 year and use of antihypertensive, lipid- or glucose-lowering medication at 1 year

${ }^{\text {a }}$ HRs are adjusted for age, sex, baseline SES, baseline BMI, smoking at 1 year, use of antihypertensive, lipid- or glucose-lowering medication at 1 year, and trial arm

${ }^{\mathrm{b}}$ Defined as $\leq 2 \%$ gain or $<2 \%$ loss at 1 year
(ESM Table 6), as were analyses excluding revascularisations and amputations (ESM Table 7). In the subdistribution hazards analysis, the associations with CVD were unchanged (ESM Table 8).

There was no evidence of an interaction between age at diabetes diagnosis and weight change $(p>0.05)$. Among those aged $\geq 65$ years at the time of diabetes diagnosis, losing $\geq 5 \%$ body weight was associated with a lower hazard of CVD compared with maintaining weight (HR 0.39 [95\% CI 0.16, 0.94]) but was not associated with all-cause mortality. Weight gain was suggestively associated with a lower hazard of CVD (HR 0.66 [95\% CI 0.20, 2.15]) and a higher hazard of mortality (HR 2.07 [95\% CI $0.81,5.30]$ ) among those aged $\geq 65$ years, albeit the results were not statistically significant (Table 3 ).

\section{Weight change and CVD risk factors}

Compared with participants who maintained weight, those who lost $\geq 5 \%$ body weight had lower $\mathrm{HbA}_{1 \mathrm{c}}$, diastolic $\mathrm{BP}$ and triacylglycerols at 1 year. At 5 years, these improvements were only apparent among those who had lost $\geq 10 \%$ weight. Total cholesterol was improved at 1 year and 5 years among those who lost $\geq 10 \%$ weight. Those who gained weight had suggestive improvements in total and LDL-cholesterol at 1 year but not at 5 years (Table 4 ). After multiple imputation of missing weight information, the observed associations were slightly stronger (ESM Table 9). After adjusting for baseline risk factor values, the results were similar (ESM Table 10).
After stratifying by relevant medication use at 1 year, participants who lost $\geq 5 \%$ body weight had lower triacylglycerols, irrespective of lipid-lowering medication use (ESM Table 11).

\section{Discussion}

In this study of 725 individuals with screen-detected type 2 diabetes, loss of $\geq 5 \%$ body weight was associated with a $48 \%$ lower 10 year hazard of CVD incidence vs maintaining weight, after adjustment for age, sex, baseline BMI, SES, smoking, medication use and trial arm. Associations were independent of changes in weight between 1 and 5 years in the study and were consistent among adults aged $\geq 65$ years at the time of diabetes diagnosis. Loss of $\geq 10 \%$ body weight was associated with improvements in $\mathrm{HbA}_{1 \mathrm{c}}$, total cholesterol and triacylglycerols at 5 years following diagnosis, which might have contributed to the observed association of weight loss and CVD events. There was no apparent association between weight loss and all-cause mortality. Weight gain was also nonstatistically significantly associated with lower hazard of CVD, but possibly higher hazard of all-cause mortality.

While extreme weight loss among people with type 2 diabetes achieved through bariatric surgery has been shown to reduce the risk of CVD [36], studies of weight loss in nonsurgery populations have shown inconsistent associations with mortality and incidence of CVD [9, 37]. A Scottish 
Table $4 \beta$ coefficients and $95 \%$ CIs derived from multivariable linear regression models of the associations of weight change in the year following diabetes diagnosis and cardiovascular risk factors measured at 1 and 5 years after diagnosis

\begin{tabular}{|c|c|c|c|c|}
\hline \multirow[t]{2}{*}{ Risk factor } & \multicolumn{2}{|c|}{ Outcomes measured at 1 year } & \multicolumn{2}{|c|}{ Outcomes measured at 5 years } \\
\hline & $n$ & $\beta(95 \% \mathrm{CI})^{\mathrm{a}}$ & $n$ & $\beta(95 \% \mathrm{CI})^{\mathrm{a}}$ \\
\hline \multicolumn{5}{|l|}{$\mathrm{HbA}_{1 \mathrm{c}}(\mathrm{mmol} / \mathrm{mol})$} \\
\hline Gained $>2 \%$ & 74 & $2.33(-0.26,4.92)$ & 71 & $-0.36(-3.45,2.73)$ \\
\hline Maintained $^{\mathrm{b}}$ & 206 & 0 & 192 & 0 \\
\hline Lost $\geq 2 \%$ to $<5 \%$ & 172 & $-1.95(-4.00,0.11)$ & 166 & $-1.25(-3.67,1.16)$ \\
\hline Lost $\geq 5 \%$ to $<10 \%$ & 129 & $-4.91(-6.54,-3.27)$ & 124 & $-1.10(-3.95,1.74)$ \\
\hline Lost $\geq 10 \%$ & 96 & $-6.92(-9.14,-4.71)$ & 90 & $-3.72(-6.28,-1.16)$ \\
\hline \multicolumn{5}{|l|}{ Systolic BP, mmHg } \\
\hline Gained $>2 \%$ & 75 & $0.93(-5.22,7.09)$ & 71 & $-0.96(-5.39,3.47)$ \\
\hline Maintained $^{\mathrm{b}}$ & 210 & 0 & 196 & 0 \\
\hline Lost $\geq 2 \%$ to $<5 \%$ & 172 & $-3.52(-6.59,-0.45)$ & 168 & $-1.47(-4.79,1.85)$ \\
\hline Lost $\geq 5 \%$ to $<10 \%$ & 131 & $-2.65(-7.04,1.74)$ & 125 & $1.67(-2.80,6.14)$ \\
\hline Lost $\geq 10 \%$ & 98 & $-4.73(-9.17,-0.29)$ & 92 & $-2.30(-6.44,1.83)$ \\
\hline \multicolumn{5}{|l|}{ Diastolic BP, mmHg } \\
\hline Gained $>2 \%$ & 75 & $0.11(-2.25,2.47)$ & 71 & $-0.45(-3.77,2.87)$ \\
\hline Maintained $^{\mathrm{b}}$ & 210 & 0 & 196 & 0 \\
\hline Lost $\geq 2 \%$ to $<5 \%$ & 172 & $-1.27(-2.90,0.36)$ & 168 & $-0.56(-2.36,1.24)$ \\
\hline Lost $\geq 5 \%$ to $<10 \%$ & 131 & $-2.37(-4.03,-0.71)$ & 125 & $-0.44(-2.32,1.44)$ \\
\hline Lost $\geq 10 \%$ & 98 & $-3.54(-5.86,-1.23)$ & 92 & $-2.41(-4.76,-0.07)$ \\
\hline \multicolumn{5}{|l|}{ Total cholesterol, mmol/1 } \\
\hline Gained $>2 \%$ & 75 & $-0.26(-0.51,-0.01)$ & 71 & $-0.11(-0.29,0.06)$ \\
\hline Maintained $^{\mathrm{b}}$ & 209 & 0 & 194 & 0 \\
\hline Lost $\geq 2 \%$ to $<5 \%$ & 173 & $-0.09(-0.26,0.09)$ & 165 & $-0.17(-0.32,-0.02)$ \\
\hline Lost $\geq 5 \%$ to $<10 \%$ & 130 & $-0.24(-0.46,-0.02)$ & 123 & $-0.15(-0.32,0.02)$ \\
\hline Lost $\geq 10 \%$ & 97 & $-0.32(-0.49,-0.15)$ & 92 & $-0.21(-0.38,-0.04)$ \\
\hline \multicolumn{5}{|l|}{ LDL-cholesterol, mmol/1 } \\
\hline Gained $>2 \%$ & 75 & $-0.25(-0.46,-0.04)$ & 68 & $-0.04(-0.23,0.15)$ \\
\hline Maintained $^{\mathrm{b}}$ & 195 & 0 & 182 & 0 \\
\hline Lost $\geq 2 \%$ to $<5 \%$ & 168 & $-0.06(-0.20,0.08)$ & 155 & $-0.19(-0.33,-0.04)$ \\
\hline Lost $\geq 5 \%$ to $<10 \%$ & 128 & $-0.12(-0.25,0.00)$ & 117 & $-0.12(-0.26,0.02)$ \\
\hline Lost $\geq 10 \%$ & 96 & $-0.12(-0.25,0.00)$ & 89 & $-0.15(-0.30,0.01)$ \\
\hline \multicolumn{5}{|l|}{ Triacylglycerols ${ }^{\mathrm{c}}, \mathrm{mmol} / \mathrm{l}$} \\
\hline Gained $>2 \%$ & 75 & $-0.11(-0.25,0.04)$ & 70 & $-0.17(-0.31,-0.03)$ \\
\hline Maintained $^{\mathrm{b}}$ & 209 & 0 & 192 & 0 \\
\hline Lost $\geq 2 \%$ to $<5 \%$ & 173 & $-0.10(-0.21,0.00)$ & 164 & $-0.07(-0.19,0.04)$ \\
\hline Lost $\geq 5 \%$ to $<10 \%$ & 130 & $-0.21(-0.33,-0.10)$ & 121 & $-0.09(-0.23,0.05)$ \\
\hline Lost $\geq 10 \%$ & 97 & $-0.46(-0.59,-0.32)$ & 90 & $-0.30(-0.42,-0.17)$ \\
\hline
\end{tabular}

Data are from a prospective cohort analysis of $N=725$ participants recruited in ADDITION-Cambridge between 2002 and 2014

${ }^{a} \beta$ coefficient values are from linear regression models adjusted for age, sex, SES, baseline BMI, smoking at 1 year, relevant medication use at 1 or 5 years, and trial arm. Coefficients represent the change in the specified outcome of interest by category of weight change, with all other variables in the model held constant

${ }^{\mathrm{b}}$ Defined as $\leq 2 \%$ gain or $<2 \%$ loss at 1 year

${ }^{\mathrm{c}}$ Calculated from $\log _{e}$ of triacylglycerols in $\mathrm{mmol} / \mathrm{l}$

observational study of weight change within 2 years of diabetes diagnosis and 5 year incidence of CVD showed no benefits of weight loss [11]. However, the magnitude of weight lost in this cohort was relatively low (mean weight change $-0.7 \% \pm$
$6.7 \%$ ) compared with the $-3.7 \% \pm 5.7 \%$ mean weight change in the current study. The ROSE study also showed no association between reductions in BMI in the 18 months following diabetes diagnosis and 5 year CVD risk [12]. While the 
magnitude of weight loss in the ROSE study was comparable to that in ADDITION-Cambridge (mean BMI decrease among those who lost weight was $2.5 \mathrm{~kg} / \mathrm{m}^{2}$, or $7.6 \%$ of baseline BMI), those who had lost weight had a higher BMI across the study period compared with those with unchanged weight. This was not the case in our study, where those who lost the most weight had a lower BMI across the study period compared with those who had maintained or gained weight (ESM Table 2). Additionally, the ROSE study had a relatively short follow-up (median 5 years) and did not control for antihypertensive medication use or smoking [38]. Furthermore, unintentional weight loss due to underlying disease might have masked any protective impact of weight loss on CVD.

One year weight loss of $\geq 10 \%$ body weight was associated with a $21 \%$ lower 10 year hazard of CVD in the Look AHEAD trial. We observed similarly strong, protective associations with $\geq 5 \%$ weight loss. This may be due to the fact that we targeted weight loss following diagnosis of diabetes via screening, whereas in Look AHEAD weight loss occurred, on average, 7 years after clinical diabetes diagnosis. Weight loss in the early stages of diabetes may result in a legacy effect to reduce long-term incidence of CVD, as was observed with short-term intensive glucose control in the UKPDS [16]. Weight loss was associated with improvements in $\mathrm{HbA}_{1 \mathrm{c}}$, lipid levels and BP at 1 year in the study. Few of these associations persisted at 5 years; however, it is possible that improvement in risk factors early on contributed to the observed lower incidence of CVD among those who lost the most weight. Furthermore, changes in BP, blood lipids and blood glucose only partially explain the mechanisms by which healthy behaviours lower CVD risk [39]. Increases in physical activity among those who lost weight might have reduced the risk of CVD through inflammatory mechanisms independently of the risk factors measured in our study.

Unintentional weight loss due to sarcopenia or cancer increases the short-term risk of mortality [40] and may be a source of unmeasured confounding in our study. To address potential confounding, we excluded deaths occurring in the year following the assessment of weight change, to reduce the likelihood that weight loss in our study was caused by disease. The protective association between weight loss and CVD risk observed in this study remained evident after restriction to participants aged $\geq 65$ years at the time of diagnosis. We cannot definitively determine that weight loss in this study was intentional and because of healthy lifestyle changes rather than age-related or cancer-related wasting; however, the fact that we excluded deaths occurring within 1 year following the initial weight loss, and that our results were robust among older participants, supports our interpretation that weight loss was unlikely to be the result of underlying disease. Unmeasured socioeconomic or baseline health differences may also modify associations with weight loss; it is possible that weight loss may be achievable and helpful for some people but unachievable or unhealthy for others. We cannot rule out the possibility that those who lost weight might have been more willing and able to healthily lose weight compared with those who did not lose weight, or the potential for other unmeasured confounding. Therefore, our results may only be applicable to people who are willing and able to lose weight.

Compared with maintaining weight, weight gain $>2 \%$ had a suggestive protective association with CVD and a suggestive adverse association with mortality. These results were not statistically significant and should be interpreted with caution, as only 75 study participants gained weight. Considering the existing literature, there is no substantiating evidence that weight gain is protective against CVD among people with type 2 diabetes. In the ROSE study, weight gain was associated with a higher hazard of 5 year all-cause mortality compared with maintaining weight [12]. Smoking cessation is associated with reduced CVD risk and weight gain; however, it is unlikely that it would have introduced confounding, as we controlled for cigarette smoking and only 17 study participants had given up smoking during the 1 year period when weight was measured. There may be heterogeneity in the associations of weight gain and CVD by baseline BMI; we adjusted for baseline BMI but we did not have a sufficient sample size to perform stratified analyses. Among those who gained weight, we might have under-ascertained CVD incidence because of the competing risk of mortality; however, as we censored participants at the time of death, person-time following a competing event was not included in the risk set. In a sensitivity analysis we estimated subdistribution HRs [35] to incorporate person-time of individuals who experienced a competing event, and the results were unchanged. Regardless, the observed associations of weight gain and CVD had poor precision and may be due to chance.

The ADDITION-Cambridge cohort was predominantly white, which limits generalisability to other populations. The majority of participants were overweight or obese at diagnosis, and although we adjusted for baseline BMI, the results would not necessarily apply to people with a normal weight or those who are underweight. We had approximately $15 \%$ missing information on weight at baseline or 1 year followup. Multiple imputation of missing information on weight showed generally similar associations, indicating results were robust to missing data under the assumption that missingness occurred at random, conditional on the covariates included in the imputation model. The relationship between weight change and CVD risk might have been confounded by health differences between those who maintained, gained or lost weight and differences in medication use across the study period. However, we adjusted for CVD risk factors including smoking, BMI, SES and cardio-protective medication use. While we adjusted for glucose-lowering medication, we were not able to separately account for metformin and sulfonylureas, as only 28 study participants were using sulfonylureas 
at 1 year. Sulfonylurea use was most common among participants who gained weight. Metformin use comprised the majority of glucose-lowering drug use in this cohort, reducing our concerns of bias related to differential effects of glucoselowering drugs on weight and CVD [41]. Exclusion of participants who reported sulfonylurea use at 1 year did not change any associations (not shown). We assessed a number of risk factors at two time points, which might have increased the probability of a type I error. However, other studies have reported similar associations between weight loss and cardiovascular risk factors [42].

Of all high-risk individuals who were invited to participate in screening, 74\% attended screening and all 867 individuals diagnosed with diabetes consented to enrol in the study, resulting in a study population which affords generalisability to the broader primary care population of eastern England. Due to the screening-based nature of this study, we were able to capture weight change during the period immediately following diabetes diagnosis, to assess whether moderate, achievable weight loss during this period can reduce longterm CVD risk. Adjustment for confounders including cigarette smoking and cardio-protective medication use improves the internal validity of our study relative to other studies of weight loss and CVD which did not adjust for these $[11,12]$.

Loss of $\geq 5 \%$ body weight during the year following diabetes diagnosis was associated with a lower hazard of CVD events at 10 years but was not associated with all-cause mortality. Weight loss $\geq 5 \%$ was also associated with improvements in $\mathrm{HbA}_{1 \mathrm{c}}$, diastolic BP and lipids at 1 year, while weight loss $\geq 10 \%$ was associated with improvements at 5 years. There is growing recognition of the impact of weight loss on diabetes remission, and our research supports the hypothesis that moderate weight loss in the year following diabetes diagnosis may yield substantial long-term CVD reduction and may be an achievable target for individuals with a new diagnosis of type 2 diabetes.

Acknowledgements We are grateful to the ADDITION-Cambridge independent trial steering committee: N. Stott (Chair; University of Cardiff, Cardiff, UK), J. Weinman (King's College, London, UK), R. Himsworth (University of Cambridge, Cambridge, UK) and P. Little (University of Southampton, Southampton, UK). Aside from the authors, the ADDITION-Cambridge study team included: A. Adler, J. Argles, G. Baker, R. Bale, R. Barling, D. Barnes, M. Betts, S. Boase, R. Butler, P. Chamnan, K. Coutts, S. Dinneen, P. Doubleday, M. Evans, T. Fanshawe, F. Finucane, P. Gash, J. Grant, W. Hardeman, R. Henderson, G. King, A.L. Kinmonth, J. Mitchell, R. Parker, N. Popplewell, A. T. Prevost, R. Salisbury, L. Sargeant, M. Smith, S. Sutton, F. Whittle and K. Williams (MRC Epidemiology Unit, University of Cambridge). We thank the Cambridge University Hospitals NHS Foundation Trust Department of Clinical Biochemistry and the National Institute for Health Research (NIHR) Cambridge Biomedical Research Centre, Core Biochemical Assay Laboratory (for carrying out the biochemical assays), and the following groups in the MRC Epidemiology Unit: data management (A. Dickinson), information technology (R. Hutchinson), technical (M. Sims), study coordination (G. Brierley and R. Salisbury) and data collection (K. Coutts).
Data availability The datasets generated and analysed during the current study are available from the corresponding author on reasonable request.

Funding ADDITION-Cambridge was supported by the Wellcome Trust (grant reference no. G061895), the Medical Research Council (MRC) (grant reference no. G0001164 and MRC Epidemiology Unit programme MC_UU_12015/4), the NIHR Health Technology Assessment Programme (grant reference no. 08/116/300), NIHR Programme Grants for Applied Research (RP-PG-0606-1259), NHS Research and Development (R\&D) support funding (including the Primary Care Research and Diabetes Research Networks) and the NIHR. SJG and NJW are NIHR senior investigators. The University of Cambridge has received salary support in respect of SJG from the NHS in the East of England through the Clinical Academic Reserve. Bio-Rad provided equipment for $\mathrm{HbA}_{1 \mathrm{c}}$ testing during the screening phase. The study sponsors were not involved in the design of the study; the collection, analysis, and interpretation of data; writing the report; or the decision to submit the report for publication.

Duality of interest SJG reports grants from the Wellcome Trust, MRC, NIHR, NIHR Health Technology Assessment Programme, NHS R\&D and the University of Aarhus (Denmark), and provision of equipment from Bio-Rad during the conduct of the study. Outside the submitted work he also reports receiving fees from Novo Nordisk, AstraZeneca and Napp for speaking at postgraduate education meetings, support to attend a scientific meeting from Napp, and an honorarium and reimbursement of travel expenses from Eli Lilly associated with membership of an independent data monitoring committee for a randomised trial of a medication to lower glucose. ALA is principal investigator on two trials where research costs are funded by national research councils (NIHR and the National Prevention Research Initiative) and where the intervention is provided at no cost by Weight Watchers International. The other authors declare that they have no conflicts of interest.

Contribution statement JS designed the study and the analysis plan, analysed the data, interpreted the results, wrote the manuscript and edited the manuscript. SJG also contributed to the design of the study and the analysis plan. ALA, GHL, MJLH, GI, CEB, NJW and SJG edited the manuscript and contributed to the interpretation of data and discussion of the study results. All authors approved the final version of the manuscript. SJG is the guarantor of this work and, as such, had full access to all the data in the study and takes responsibility for the integrity of the data and the accuracy of the data analysis.

Open Access This article is distributed under the terms of the Creative Commons Attribution 4.0 International License (http:// creativecommons.org/licenses/by/4.0/), which permits unrestricted use, distribution, and reproduction in any medium, provided you give appropriate credit to the original author(s) and the source, provide a link to the Creative Commons license, and indicate if changes were made.

\section{References}

1. Einarson TR, Acs A, Ludwig C, Panton UH (2018) Prevalence of cardiovascular disease in type 2 diabetes: a systematic literature review of scientific evidence from across the world in 2007-2017. Cardiovasc Diabetol 17(1):83. https://doi.org/10.1186/s12933-0180728-6

2. Einarson TR, Acs A, Ludwig C, Panton UH (2018) Economic burden of cardiovascular disease in type 2 diabetes: a systematic review. Value Health 21(7):881-890. https://doi.org/10.1016/j.jval. 2017.12.019 
3. Diabetes UK (2014) The cost of diabetes: report. Available form www.diabetes.org.uk/resources-s3/2017-11/diabetes\%20uk\% 20 cost $\% 20$ of $\% 20$ diabetes\%20report.pdf. Accessed 1 October 2018

4. Look AHEAD Research Group (2010) Long-term effects of a lifestyle intervention on weight and cardiovascular risk factors in individuals with type 2 diabetes mellitus: four-year results of the Look AHEAD trial. Arch Intern Med 170(17):1566-1575

5. Franz MJ, Boucher JL, Rutten-Ramos S, VanWormer JJ (2015) Lifestyle weight-loss intervention outcomes in overweight and obese adults with type 2 diabetes: a systematic review and metaanalysis of randomized clinical trials. J Acad Nutr Diet 115(9): 1447-1463. https://doi.org/10.1016/j.jand.2015.02.031

6. The Look AHEAD Research Group (2013) Cardiovascular effects of intensive lifestyle intervention in type 2 diabetes. N Engl J Med 369(2):145-154. https://doi.org/10.1056/NEJMoa1212914

7. Lean ME, Leslie WS, Barnes AC et al (2018) Primary care-led weight management for remission of type 2 diabetes (DiRECT): an open-label, cluster-randomised trial. Lancet 391(10120):541551. https://doi.org/10.1016/S0140-6736(17)33102-1

8. Wing RR, Lang W, Wadden TA et al (2011) Benefits of modest weight loss in improving cardiovascular risk factors in overweight and obese individuals with type 2 diabetes. Diabetes Care 34(7): 1481-1486. https://doi.org/10.2337/dc10-2415

9. Williamson DF (1998) Weight loss and mortality in persons with type-2 diabetes mellitus: a review of the epidemiological evidence. Exp Clin Endocrinol Diabetes 106(Suppl 2):14-21

10. Gregg EW, Jakicic JM, Blackburn G et al (2016) Association of the magnitude of weight loss and changes in physical fitness with longterm cardiovascular disease outcomes in overweight or obese people with type 2 diabetes: a post-hoc analysis of the Look AHEAD randomised clinical trial. Lancet Diabetes Endocrinol 4(11):913-921

11. Aucott LS, Philip S, Avenell A, Afolabi E, Sattar N, Wild S (2016) Patterns of weight change after the diagnosis of type 2 diabetes in Scotland and their relationship with glycaemic control, mortality and cardiovascular outcomes: a retrospective cohort study. BMJ Open 6(7):e010836. https://doi.org/10.1136/bmjopen-2015010836

12. Bodegard J, Sundstrom J, Svennblad B, Ostgren CJ, Nilsson PM, Johansson G (2013) Changes in body mass index following newly diagnosed type 2 diabetes and risk of cardiovascular mortality: a cohort study of 8486 primary-care patients. Diabetes Metab 39(4): 306-313. https://doi.org/10.1016/j.diabet.2013.05.004

13. Gorin AA, Phelan S, Hill JO, Wing RR (2004) Medical triggers are associated with better short- and long-term weight loss outcomes. Prev Med 39(3):612-616. https://doi.org/10.1016/j.ypmed.2004. 02.026

14. Patel A, MacMahon S, Chalmers J et al (2008) Intensive blood glucose control and vascular outcomes in patients with type 2 diabetes. N Engl J Med 358(24):2560-2572

15. Ismail-Beigi F, Craven T, Banerji MA et al (2010) Effect of intensive treatment of hyperglycaemia on microvascular outcomes in type 2 diabetes: an analysis of the ACCORD randomised trial. Lancet 376(9739):419-430. https://doi.org/10.1016/S01406736(10)60576-4

16. Holman RR, Paul SK, Bethel MA, Matthews DR, Neil HA (2008) 10-year follow-up of intensive glucose control in type 2 diabetes. $\mathrm{N}$ Engl J Med 359(15):1577-1589. https://doi.org/10.1056/ NEJMoa0806470

17. Koster-Rasmussen R, Simonsen MK, Siersma V, Henriksen JE, Heitmann BL, de Fine Olivarius N (2016) Intentional weight loss and longevity in overweight patients with type 2 diabetes: a population-based cohort study. PLoS One 11(1):e0146889. https:// doi.org/10.1371/journal.pone.0146889

18. Piepoli MF, Hoes AW, Agewall S et al (2016) 2016 European guidelines on cardiovascular disease prevention in clinical practice: the Sixth Joint Task Force of the European Society of Cardiology and other societies on cardiovascular disease prevention in clinical practice (constituted by representatives of 10 societies and by invited experts): developed with the special contribution of the European Association for Cardiovascular Prevention \& Rehabilitation (EACPR). Eur Heart J 37(29):2315-2381

19. Echouffo-Tcheugui JB, Simmons RK, Williams KM et al (2009) The ADDITION-Cambridge trial protocol: a cluster-randomised controlled trial of screening for type 2 diabetes and intensive treatment for screen-detected patients. BMC Public Health 9(1):136. https://doi.org/10.1186/1471-2458-9-136

20. Griffin SJ, Little PS, Hales CN, Kinmonth AL, Wareham NJ (2000) Diabetes risk score: towards earlier detection of type 2 diabetes in general practice. Diabetes Metab Res Rev 16(3):164-171. https:// doi.org/10.1002/1520-7560(200005/06)16:3<164::AIDDMRR103>3.0.CO;2-R

21. Sargeant LA, Simmons RK, Barling RS et al (2010) Who attends a UK diabetes screening programme? Findings from the ADDITION-Cambridge study. Diabet Med 27(9):995-1003. https://doi.org/10.1111/j.1464-5491.2010.03056.x

22. World Health Organization Definition, diagnosis and classification of diabetes mellitus and its complications. Part 1: diagnosis and classification of diabetes mellitus. Geneva: WHO, 1999. Available from https://apps.who.int/iris/handle/10665/66040. Accessed 1 October 2018

23. McIntosh $\mathrm{A}$, Hutchinson $\mathrm{A}$, Home $\mathrm{P}$ et al Clinical guidelines and evidence review for type 2 diabetes: blood glucose management. Sheffield: ScHARR, University of Sheffield. 2001. Available from https://www.nice.org.uk/guidance/g/documents/type-2-diabetesglycaemic-control2. Accessed 1 November 2018

24. Hutchinson A, McIntosh A, Griffiths $\mathrm{C}$ et al Clinical guidelines and evidence review for type 2 diabetes: management of blood pressure. Sheffield: ScHARR, University of Sheffield. 2002. Available from https://www.nice.org.uk/guidance/ng28/chapter/1 recommendations\#blood-pressure-management-2 . Accessed 1 November 2018

25. McIntosh A, Hutchinson A, Feder G et al Clinical guidelines and evidence review for type 2 diabetes: lipids management. Sheffield: ScHARR, University of Sheffield. 2002. Available from https:// www.academia.edu/2978743/Clinical guidelines and evidence review_for_type_2_diabetes_lipids_management. Accessed 1 November 2018

26. Elias P, Halstead K, Prandy K (1993) CASOC: computer-assisted standard occupational coding. HMSO, London

27. Herrett E, Smeeth L, Walker L, Weston C, Group MA (2010) The Myocardial Ischaemia National Audit Project (MINAP). Heart 96(16):1264-1267. https://doi.org/10.1136/hrt.2009.192328

28. Blackburn G (1995) Effect of degree of weight loss on health benefits. Obes Res 3(Suppl 2):211s-216s. https://doi.org/10.1002/j. 1550-8528.1995.tb00466.x

29. National Institutes of Health (1998) Clinical guidelines on the identification, evaluation, and treatment of overweight and obesity in adults - the evidence report. National Institutes of Health. Obes Res 6(Suppl 2):51S-209S

30. Greenland S, Pearl J, Robins JM (1999) Causal diagrams for epidemiologic research. Epidemiology 10(1):37-48. https://doi.org/ 10.1097/00001648-199901000-00008

31. Lee CG, Boyko EJ, Nielson CM et al (2011) Mortality risk in older men associated with changes in weight, lean mass, and fat mass. J Am Geriatr Soc 59(2):233-240. https://doi.org/10.1111/j.15325415.2010.03245.x

32. Wedick NM, Barrett-Connor E, Knoke JD, Wingard DL (2002) The relationship between weight loss and all-cause mortality in older men and women with and without diabetes mellitus: the Rancho Bernardo study. J Am Geriatr Soc 50(11):1810-1815. https://doi. $\operatorname{org} / 10.1046 / j .1532-5415.2002 .50509 . x$ 
33. Murphy RA, Patel KV, Kritchevsky SB et al (2014) Weight change, body composition, and risk of mobility disability and mortality in older adults: a population-based cohort study. J Am Geriatr Soc 62(8):1476-1483. https://doi.org/10.1111/jgs. 12954

34. White IR, Carlin JB (2010) Bias and efficiency of multiple imputation compared with complete-case analysis for missing covariate values. Stat Med 29(28):2920-2931. https://doi.org/10.1002/sim. 3944

35. Fine JP, Gray RJ (1999) A proportional hazards model for the subdistribution of a competing risk. J Am Stat Assoc 94(446): 496-509. https://doi.org/10.1080/01621459.1999.10474144

36. Eliasson B, Liakopoulos V, Franzen S et al (2015) Cardiovascular disease and mortality in patients with type 2 diabetes after bariatric surgery in Sweden: a nationwide, matched, observational cohort study. Lancet Diabetes Endocrinol 3(11):847-854. https://doi.org/ 10.1016/S2213-8587(15)00334-4

37. Ryan DH, Yockey SR (2017) Weight loss and improvement in comorbidity: differences at $5 \%, 10 \%, 15 \%$, and over. Curr Obes Rep 6(2):187-194. https://doi.org/10.1007/s13679-017-0262-y

38. Bronte-Stewart B (1961) Cigarette smoking and ischaemic heart disease. Br Med J 1(5223):379-384. https://doi.org/10.1136/bmj. 1.5223 .379
39. Mora S, Cook N, Buring JE, Ridker PM, Lee IM (2007) Physical activity and reduced risk of cardiovascular events: potential mediating mechanisms. Circulation. 116(19):2110-2118. https://doi.org/ 10.1161/CIRCULATIONAHA.107.729939

40. Kalyani RR, Corriere M, Ferrucci L (2014) Age-related and disease-related muscle loss: the effect of diabetes, obesity, and other diseases. Lancet Diabetes Endocrinol 2(10):819-829. https://doi. org/10.1016/S2213-8587(14)70034-8

41. Ferrannini E, DeFronzo RA (2015) Impact of glucose-lowering drugs on cardiovascular disease in type 2 diabetes. Eur Heart J 36(34):2288-2296. https://doi.org/10.1093/eurheartj/ehv239

42. Fujioka K (2010) Benefits of moderate weight loss in patients with type 2 diabetes. Diabetes Obes Metab 12(3):186-194. https://doi. org/10.1111/j.1463-1326.2009.01155.x

Publisher's note Springer Nature remains neutral with regard to jurisdictional claims in published maps and institutional affiliations. 